UDC 347.775

LBC 67.404.213.6

\title{
ADAPTABILITY OF MEDIATION ACTIVITIES ${ }^{1}$
}

\author{
Roman G. Melnichenko \\ Volgograd State University, Volgograd, Russian Federation
}

\begin{abstract}
Introduction: the successful development of any activity, including activities in the social sphere, is impossible without its introduction into the technological discourse. Using the experience in the legal and psychological science the author has set the goal to explore the technology in the mediation activities. As a task the author has conducted the research of the individual mediation techniques. Methods: the methodological basis for the research is a set of the following methods of scientific knowledge: the comparative and scientific method, the methods of systemacity and analysis. Results: the author suggests classifying the technology into two types: technology as a method and technology as a tool. In turn, the author distinguishes the following types of the mediation technology as a method: echo technique, caucus, externalization, deconstruction and rewriting. Following the logic of the technological approach, there has been shown the algorithm of the use of such a technology as mediation: echo technique and caucus. There has been proposed the three-part algorithm for the deployment of each mediation technology. In developing these technologies there have been defined the shortcomings of each of them. Conclusions: the technological approach to the mediation activities is very promising both from the standpoint of the science in which there occur the identification and fixation of the mediation techniques and from the law enforcement practice where these technologies can be applied.
\end{abstract}

Key words: mediation, technology, echo-tech, caucus, externalization, deconstruction, rewriting.

УДК 347.775

ББК 67.404.213.6

\section{ТЕХНОЛОГИЧНОСТЬ МЕДИАЦИОННОЙ ДЕЯТЕЛЬНОСТИ ${ }^{1}$}

\author{
Роман Григорьевич Мельниченко \\ Волгоградский государственный университет, г. Волгоград, Российская Федерация
}

\begin{abstract}
Введение: успешное развитие какой-либо деятельности, в том числе деятельности в социальной сфере, невозможно без введения ее в технологический дискурс. Используя опыт юридической и психологической науки, поставлена цель исследовать технологии в медиационной деятельности. В качестве задачи взято исследование алгоритмов отдельных медиационных технологий. Методы: методологическую основу исследования составляет совокупность следующих методов научного познания: сравнительно-научный метод, метод системности и метод анализа. Результаты: автором предлагается классификация технологий на два вида: технология как метод и технология как инструмент. В свою очередь выделяются следующие виды медиационных технологий как метода: эхо-техника, кокус, экстернализа- ция, деконструкция и пересочинение. Следуя логике технологического подхода, представлен алгоритм 흘 применения таких медиационных технологий, как эхо-техника и кокус. Предложен трехчастный алгор ритм развертывания каждой медиационной технологии. В ходе построения данных технологий были выявлены «слабые места» каждой из них. Выводы: технологический подход к медиационной деятельности является весьма перспективным как с позиции науки, в рамках которой происходят идентификация и фиксация медиационных технологий, так и правоприменительной практики, где эти технологии могут применяться.

Ключевые слова: медиация, технология, эхо-техника, кокус, экстернализация, деконструкция, пересочинение.
\end{abstract}




\section{Введение}

Сегодня общепринятым является утверждение, что «на сегодняшний день ни у законодателя, ни у специалистов, занимающихся подготовкой медиаторов в Российской Федерации, нет никакого четкого представления о том, что представляет собой на самом деле медиация» [6, с. 80]. На этом фоне ключевой ценностью медиации стали применяемые в ходе медиационных процедур технологии [1, с. 158]. Под технологией (с гр. techne - искусство и logos - слово, учение) сегодня понимается совокупность методов и инструментов для достижения желаемого результата; в широком смысле применение научного знания для решения практических задач [5, с. 305]. Из определения легко вычленить два вида технологий: технология как метод и технология как инструмент. Технология как инструмент - это использование в какой-либо деятельности материальных «орудий», например, средств коммуникаций (сеть Интернет) или электронно-вычислительных машин. Орудия применяются в медиационной деятельности, например, в ходе дистанционного примирения, но настоящая статья посвящена методам-технологиям.

Методы-технологии - это процедуры, применяя которые участники процесса достигают поставленных перед ними целей. Признаком методов-технологий является наличие цели, структуры при одновременной инвариантности (гибкости) применения.

В медиационной деятельности был разработан ряд методов-технологий, которые успешно применяются в ходе примирительных процедур. В широком смысле сама медиация является технологией, так как она разделена на три стадии: предмедиационную, медиационную (медиационная сессия) и постмедиационную. Каждая стадия в свою очередь разделена на определенные этапы. Каждый этап строго регламентирован, имеет свою процедуру и задачи. Существуют в медиации и локальные методы-технологии, которые могут применяться в случае необходимости на различных стадиях медиационного процесса. Рассмотрим два локальных медиационных метода-технологии: эхо-технику и кокус.

\section{Эхо-техника}

Эхо-техника - это медиационная техника, которая заключается в рефлектированном слушании и повторении слов говорящего. В Россию подобная техника пришла несколько раньше, чем сама медиация, по каналам психологического консультирования, где она называется активным, или эмпатическим, слушанием [2, с. 5]. Повтор (эхо) является одним из приемов активного слушания. С приходом медиации эхо-техника в контексте урегулирования конфликтов претерпела «второе пришествие» $[3$, с. 148$]$.

Эхо-техника является видом рефлексивного слушания, в ходе которого говорящий уверен, что:

- слушающий его слушает;

- слушающий его слышит;

- слушающий ему сопереживает (эмпатический аспект).

Необходимо привести несколько примеров применения эхо-техники в медиационной деятельности, которые продемонстрируют возможности этой технологии, ее функционал:

1. Побуждение к высказываниям. В ходе изложения своей истории (презентация) на первой стадии медиационной сессии сторона может по различным причинам испытывать трудности в проговаривании своего рассказа. Причинами могут являться страх, косноязычие и т. п. При помощи повторения части фразы говорящего медиатор побуждает сторону продолжать и активизировать говорение.

2. Прояснение понимания. Медиатор повторяет с вопросительной интонацией непонятное ему в речи говорящего место. Последний возвращается к этому месту своей речи и или перефразирует ее, или раскрывает более подробно. При этом могут обнаружиться важные для разрешения спора обстоятельства. В контексте активного слушания эти приемы называются уточнением и перефразом. Уточнение - это просьба уточнить или разъяснить что-либо из сказанного. Пересказ (парафраз) - это попытка слушателя кратко и своими словами повторить изложенное собеседником.

3. Удержание эмоционального фона требуется в случае, когда рассказчик сильно возбужден. Чтобы успокоить доверите- 
ля, медиатор повторяет спокойным тоном услышанные в речи говорящего нейтрально окрашенные фразы, например: «пришел к выводу», «успокоился», «понял». В психологии эта функция эмпатического слушания является основной.

Технологический процесс эхо-техники зависит от той задачи, которая стоит перед медиатором, но во всех случаях включает в себя три этапа: идентификацию, применение и завершение. Рассмотрим эти процедуры на вышеприведенных примерах.

Побуждение к высказываниям. Задача этапа идентификации в этом случае заключается в понимании медиатором того обстоятельства, что один из участников медиационного процесса скупится на коммуникацию, то есть, например, отвечает односложно. Признаки подобной коммуникационной трудности могут быть следующие: продолжительные паузы, короткие предложения, закрытая поза. Второй этап - применение - состоит из двух тактов: выявление ключевого слова и составление предложения с этим ключевым словом. Выявление ключевого слова в речи возможно по нескольким признакам: пауза до или перед словом, интонационное выделение (увеличение громкости, экспираторность и т. п.), невербальное выделение (мимикой, жестом, позой). Например, в ходе произнесения фразы «Она своей болтовней отвлекает меня от работы» на слове «отвлекает» говорящий (участник медиационной сессии) увеличил громкость своей речи и ударил пальцами по столу.

Составление предложения с ключевым словом - это включение выявленного слова в свое обращение к стороне. Например, после вышеприведенной фразы медиатор может спросить: «Любая речь И. отвлекает или какая-то определенная?» Логическое ударение медиатор делает на слове «отвлекает».

Завершение применения эхо-техники также важнейший этап. Дело в том, что после начала эхо-технической процедуры стороны могут «увлечься». Необходимо понять, когда технология эхо-техники сработала, и если задачи выполнены, ее можно прекратить. Например, сторона «разговорилась», значит, пришло время просто ее слушать.

Подобный алгоритм существует и для эхо-техники при постановке задачи проясне- ния понимания и удержания эмоционального фона.

Прояснение понимания. На этапе идентификации медиатор должен понять, что он чего-то не понимает в речи говорящего. Для этого необходимо включить детский (наивный) режим слушания. Маркерами непонимания могут быть торопливая речь говорящего, утеря медиатором нити повествования, не понятные для слушающего термины. На втором этапе медиатор формулирует вопрос о непонятном в речи доверителя и выслушивает ответ. На заключительном этапе целесообразно повторить ответ говорящего, перефразируя его. Например, на фразу доверителя «Она же не рефлексирует свое поведение!» медиатор может спросить: «Что значит не рефлексирует?»

Удержание эмоционального фона также начинается с идентификации проблемы. В качестве идентификаторов здесь могут служить следующие признаки: повышение тона у говорящего, активизация жестикуляции, использование эмоциональных терминов (страх, жуть, убийственно и т. п.). Например, доверительница, резко повышая громкость своей речи, говорит: «Он меня никогда не понимал!» На втором этапе медиатор очищает фразу от эмоционально-негативных слов и негромко, спокойно произносит: «Он Вас не понимает». Очевидно, что во фразе доверительницы эмоционально окрашенным словом было слово «никогда», которое не только повышает негативный эмоциональный модус, но и препятствует примирению.

В некоторых формах применения медиации, например в уголовном процессе, удержание эмоционального фона становится для медиатора важнейшей задачей. «Практика показывает, что потерпевший в большинстве случаев не ставит материальное возмещение ущерба во главу угла. Куда важнее душевные переживания в связи с направленным против него преступлением» [4, с. 207].

Существуют и опасности в применении эхо-техники, на которых необходимо остановиться:

1. Эффект плохо слышащего. В том случае, если медиатор излишне часто повторяет фразы за говорящим, это может начать раздражать последнего. Кроме необходимости 
соблюдать меру, можно посоветовать медиаторам в этом случае использовать перефраз.

2. Перебивание. Эхо-техника может восприниматься в качестве акта перебивания (чем она, собственно, и является), а следовательно, может быть рассмотрена стороной как нежелание медиатора ее слушать. Коммуникация в этом случае может прерваться.

3. Навязывание. Исходя из принципа ответственности сторон за принимаемое ими решение медиатор должен весьма аккуратно предлагать сторонам свое видение проблемы. Эхо-техника может послужить весьма опасным инструментом влияния медиатора на волю сторон. В психологии подобное свойство эхо-техники даже приветствуется. Ю.Б. Гиппенрейтер указывает: «Активно слушать ребенка - значит “возвращать” ему в беседе то, что он вам поведал, при этом обозначив его чувство.

Сын: Он отнял мою машинку!

Мама: Ты очень огорчен и рассержен на него» [2, с. 1]. Действительно, возможно сын огорчен и рассержен, а если нет?

Профессиональный медиатор так бы использовал прием обобщения:

Доверитель: Он отнял мой бизнес.

Медиатор: Какие чувства Вы при этом испытали?

\section{Кокус}

Кокус (caucus) в первом своем значении - это собрание сторонников политической партии. Затем оно получило значение закрытого (кулуарного) собрания. Применение процедуры кокуса можно увидеть и в юридической деятельности. Например, право доверителя посоветоваться со своим адвокатом, практика «кулуарного» общения судьи с профессиональными участниками процесса (адвокатом и прокурором). В медиации под кокусом понимается медиационная техника, которая заключается в индивидуальной беседе с одной из сторон. Технически кокус происходит следующим образом. Медиатор идентифицирует необходимость в проведении индивидуальной беседы с одной из сторон. Он объявляет об этом сторонам и удаляется с одной из них в отдельное помещение вне зоны слышимости другой стороны.
Кокус является инструментом медиатора, поэтому его применение может быть весьма разнообразно, причем на любой стадии медиационного процесса. Приведем лишь несколько примеров применения кокуса в работе медиатора:

1. Понижение эмоционального фона. При повышении эмоционального фона существует угроза прерывания коммуникации. Кокус помогает в прямом смысле физически развести спорящие стороны. Медиатор удаляется с наиболее эмоциональной стороной и проводит процедуру ее «успокаивания».

2. Предупреждение одной стороны. В том случае, если медиатор идентифицировал поведение одной из сторон как поведение, нарушающее принципы медиации, он может провести с этой стороной кокус. Например, указать стороне, что она ведет себя так, как будто хочет использовать медиацию для затягивания времени, манипулирования другой стороной и т. п. Если сказать об этом в присутствии другой стороны, это может негативно повлиять на процедуру медиации.

3. Ступор стороны. Медиатор видит, что одна из сторон перестает понимать, что происходит, потеряла нить разговора, и при этом не решается сказать об этом. В ходе кокуса медиатор соответствующими вопросами способствует выработке понимания ситуации стороной.

Необходимо выделить основные принципы кокуса:

1. Информированное согласие на кокус. Сторонам должен быть предварительно и неоднократно объяснен механизм кокуса. Обе стороны должны выразить свое согласие на применение кокуса в процедуре медиации. Информирование целесообразно провести и на предмедиационной стадии (при подготовке к сессии), на самой медиационной сессии, например, во вступительном слове медиатора, непосредственно перед применением кокуса.

2. Равное право на кокус. Обе стороны имеют право на кокус. Так, в случае, если медиатор провел с одной из сторон кокус, он должен провести такую же процедуру или хотя бы предложить ее другой стороне. В соответствии с принципом равноправия сторон количество кокусов, а также время, затраченное на них, должно быть хотя бы примерно оди- 
наковым, для того чтобы одна сторона не могла обвинить медиатора в симпатии к другой стороне.

Как и любой инструмент, кокус таит в себе опасность. То есть перед тем, как воспользоваться этим инструментом, медиатор должен подумать о тех рисках, которые существуют при применении кокуса. И если риск высок и не оправдывает ту пользу, которую медиатор надеется получить от процедуры кокуса, от нее лучше отказаться. Перечислим возможные негативные побочные эффекты кокуса:

1. Разрыв коммуникации. Если коммуникационные связи слабы, то после кокуса медиатор должен быть готов к тому, что ему придется приложить определенные усилия к восстановлению (воссозданию) этих связей.

2. Непрозрачность. Даже после того как информированное согласие на проведение кокуса у сторон получено, после удаления медиатора с одной стороной на кокус у оставшейся стороны возникает ощущение отстраненности от процесса и неизвестности того, что там происходит. А неизвестность может заполниться стороной самостоятельно, то есть она может предположить, о чем беседует медиатор с другой стороной. И, скорее всего, эти фантазии будут не на пользу медиационной процедуре.

\section{Результаты}

Проведена классификация технологий медиационной деятельности. Составлен алгоритм двух медиационных технологий: эхо-техники и кокуса. Обозначены проблемы применения разработанных алгоритмов.

\section{Выводы}

Представленные медиационные технологии не являются единственными, например, такое направление, как нарративная медиация, обладает как минимум еще тремя уникальными технологиями: экстернализацией, деконструкцией и пересочинением. Более того, сами технологии в ходе практического применения модифицируются. Задачи ученых в области медиации - идентификация технологий, их описание и популяризация.

\section{ПРИМЕЧАНИЕ}

${ }^{1}$ Исследование выполнено при финансовой поддержке РГНФ и Администрации Волгоградской области в рамках проекта проведения научных исследований «Медиативные технологии снижения социальной конфликтности в деятельности должностных лиц органов местного самоуправления Волгоградской области», проект № 16-13-34020.

\section{СПИСОК ЛИТЕРАТУРЫ}

1. Геворкян, Т. В. Медиация как один из альтернативных способов разрешения споров и ее влияние на правовую культуру общества / Т. В. Геворкян // Вестник Волгоградского государственного университета. Серия 5, Юриспруденция. - 2013. № 1 (18). - С. 155-158.

2. Гиппенрейтер, Ю. Б. Чудеса активного слушания / Ю. Б. Гиппенрейтер. - М. : АСТ, 2013. 192 c.

3. Мельниченко, Р. Г. Медиация / Р. Г. Мельниченко. - М. : Дашков и К, 2014. - 192 с.

4. Перекрестов, В. Н. Признание вины как условие медиации в уголовном процессе / В. Н. Перекрестов // Вестник Волгоградского государственного университета. Серия 5, Юриспруденция. 2011. - № 1 (14). - С. 205-209.

5. Райзберг, Б. А. Современный экономический словарь / Б. А. Райзберг, Л. Ш. Лозовский, Е. Б. Стародубцева. - М. : Инфра-М, 1999. - 479 с.

6. Трофимов, Я. В. Современное развитие медиации в Российской Федерации: правовые или неправовые принципы составляют ее основу? / Я. В. Трофимов // Вестник Волгоградского государственного университета. Серия 5, Юриспруденция. -2013. - № 1 (18). - С. 76-80.

\section{REFERENCES}

1. Gevorkyan T.V. Mediatsiya kak odin iz alternativnykh sposobov razresheniya sporov i ee vliyanie na pravovuyu kulturu obshchestva [Mediation as One of the Alternative Ways of Resolving Disputes and Its Impact on the Legal Culture of Society]. Vestnik Volgogradskogo gosudarstvennogo universiteta. Seriya 5, Yurisprudentsiya [Science Journal of Volgograd State University. Jurisprudence], 2013, no. 1 (18), pp. 155-158.

2. Gippenreyter Yu.B. Chudesa aktivnogo slushaniya [Miracles of Active Listening]. Moscow, AST Publ., 2013. 192 p.

3. Melnichenko R.G. Mediatsiya [Mediation]. Moscow, Dashkov i K Publ., 2014. 92 p. 
4. Perekrestov V.N. Priznanie viny kak uslovie mediatsii v ugolovnom protsesse [Recognition of Guilt as a Condition of Mediation in the Criminal Process]. Vestnik Volgogradskogo gosudarstvennogo universiteta. Seriya 5, Yurisprudentsiya [Science Journal of Volgograd State University. Jurisprudence], 2011, no. 1 (14), pp. 205-209.

5. Rayzberg B.A., Lozovskiy L.Sh., Starodubtseva E.B. Sovremennyy ekonomicheskiy slovar [Modern Economic Dictionary]. Moscow, InfraM Publ., 1999.479p.
6. Trofimov Ya.V. Sovremennoe razvitie mediatsii v Rossiyskoy Federatsii: pravovye ili nepravovye printsipy sostavlyayut ee osnovu? [Modern Development of Mediation in the Russian Federation: Legal or Non-Legal Principles Constitute Its Basis?]. Vestnik Volgogradskogo gosudarstvennogo universiteta. Seriya 5, Yurisprudentsiya [Science Journal of Volgograd State University. Jurisprudence], 2013, no. 1 (18), pp. 76-80.

\section{Information about the Author}

Roman G. Melnichenko, Candidate of Juridical Sciences, Associate Professor, Leading Researcher of the Institute of Law, Volgograd State University, Prosp. Universitetsky, 100, 400062 Volgograd, Russian Federation, melnichenko@volsu.ru.

\section{Информация об авторе}

Роман Григорьевич Мельниченко, кандидат юридических наук, доцент, ведущий научный сотрудник института права, Волгоградский государственный университет, просп. Университетский, 100, 400062 г. Волгоград, Российская Федерация, melnichenko@volsu.ru. 